\title{
Percebendo-se como um herói no enfrentamento da dermatite atópica: a percepção do pré-escolar
}

\begin{abstract}
RESUMO | O estudo objetivou compreender a experiência da criança com Dermatite Atópica em relação ao enfrentamento da doença por meio do conteúdo expresso na brincadeira, à luz do Interacionismo Simbólico. Trata-se de pesquisa qualitativa, realizada em uma unidade ambulatorial filantrópica em São Paulo-SP, com crianças em fase pré-escolar. Este percebeu que o viver com dermatite atópica é marcado por uma série de restrições. Os resultados permitiram compreender a experiência vivenciada pela criança pré-escolar com dermatite atópica e entender como esta condição interfere em sua vida e na interação com o ambiente à sua volta. O brinquedo mostrou-se como um aliado da criança no enfrentamento da doença e importante ferramenta de coleta de dados, possibilitando à criança expressar-se com liberdade. Este avançou no conhecimento sobre o tema e pode auxiliar o enfermeiro na decisão por ações centradas na criança e em sua perspectiva, contribuindo para aprimorar a qualidade da assistência de enfermagem.
\end{abstract}

Palavras-chaves: Jogos e Brinquedos; Enfermagem Pediátrica; Dermatite Atópica.

ABSTRACT | The research aimed to understand the experience of the child with Atopic Dermatitis in relation to the confrontation of the disease through the content expressed in the game, by the light of Symbolic Interactionism. This is a qualitative research, carried out in a philanthropic outpatient unit in São Paulo, Brazil, with pre-school children. The results allowed us to understand the experience of preschool children with atopic dermatitis and to understand how this condition interferes with their life and their interaction with the environment around them. The therapeutic play proved to be an ally of the child in overcoming his hardships and proved to be an important data collection tool that enables the child to express himself with freedom. It has advanced in the knowledge about the subject and can help nurses in the decision for actions centered on the child and their perspective, contributing to improve the quality of nursing care.

Keywords: Play and Playthings; Pediatric Nursing; Atopic Dermatitis.

RESUMEN | El estudio objetivó comprender la experiencia del niño con Dermatitis Atópica en relación al enfrentamiento de la enfermedad por medio del contenido expresado en la broma, a la luz del Interaccionismo Simbólico. Se trata de una investigación cualitativa, realizada en una unidad ambulatorial filantrópica en São Paulo-SP, con niños en fase preescolar. Este percibió que el vivir con dermatitis atópica está marcado por una serie de restricciones. Los resultados permitieron comprender la experiencia vivenciada por el niño preescolar con dermatitis atópica y entender cómo esta condición interfiere en su vida y en la interacción con el ambiente a su alrededor. El juguete se mostró como un aliado del niño en el enfrentamiento de la enfermedad e importante herramienta recolecta de datos, permitiendo al niño expresarse con libertad. Este avanzó en el conocimiento sobre el tema y puede auxiliar al enfermero en la decisión por acciones centradas en el niño y en su perspectiva, contribuyendo a mejorar la calidad de la asistencia de enfermería.

Descriptores: Juegos y Juguetes; Enfermería Pediátrica; Dermatitis Atopica.

\section{Isabelline Freitas Dantas Paiva de Almeida}

Enfermeira, Mestre em Enfermagem, Docente, Faculdade de Enfermagem Nova Esperança (FACENE), Mossoró, Rio Grande do Norte.

\section{Fabiane de Amorim Almeida}

Enfermeira, Doutora em Enfermagem, Docente, Faculdade Israelita de Ciências da Saúde Albert Einstein, São Paulo, SP

\section{Circea Amália Ribeiro}

Enfermeira, Doutora em Enfermagem, Docente Associada, Universidade Federal de São Paulo, São Paulo, SP

\section{Mariana Lucas da Rocha Cunha}

Enfermeira, Doutora em Enfermagem, Docente, Faculdade Israelita de Ciências da Saúde Albert Einstein, São Paulo, SP

\section{Fabiana Lopes Pereira Santana}

Enfermeira, Doutoranda em Enfermagem, Universidade de São Paulo, São Paulo, SP

\section{Monica Miranda Pereira Sanchez}

Enfermeira, Mestre em Enfermagem, Supervisora de Enfermagem, Hospital São Camilo, São Paulo, SP

Recebido em: 26/04/2019 Aprovado em: 25/05/2019
INTRODUÇÃO

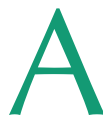
Dermatite Atópica (DA), também chamada de eczema atópico, é uma doença crônica de pele ${ }^{(1)}$. Ela caracteriza-se por lesões eczematosas e recidivantes, as quais estão associadas a intenso prurido e pele seca $^{(2)}$. É a doença de pele recidivante mais comum entre crianças e lactentes com tendência a ser mais grave e persistente nestas fases. Ela atinge em média 10 - 30\% das crianças menores de 5 anos de idade em todo o mundo ${ }^{(1)}$.

O surgimento da DA tem causa multifatorial, está relacionada a fatores genéticos e ambientais ${ }^{(3)}$. Dentre as causas que exacerbam a doença, estão: o estilo de vida, estado nutricional, localização geográfica e clima do local onde essas pesso- 
as residem ${ }^{(2)}$. Soma-se a isso a afirmativa de que a pele da pessoa com DA é fortemente susceptível a fatores ambientais irritantes, alérgenos e micróbios ${ }^{(3)}$. Além destes, há relação do fator emocional no desencadeamento da doença ${ }^{(4)}$.

As manifestações clínicas da doença demandam uma série de restrições à pessoa que tem a Dermatite Atópica ${ }^{(5)}$, interferindo significativamente nos aspectos cotidianos da criança, como o padrão de sono e comprometendo as atividades de lazer ou impactando no rendimento escolar, entre outros ${ }^{(6)}$.

O tratamento da DA é fundamentado no autocuidado, hidratação cutânea adequada, adesão à terapia medicamentosa e abstenção aos fatores que podem exacerbar a doença. Isso implica em uma rotina de cuidados e tratamentos, os quais nem sempre surtem efeitos imediatos ${ }^{(5)}$.

Ao conhecer a problemática que permeia a vida das crianças com DA e sabendo que, enquanto brinca, a criança se doa ao mundo por inteiro, faz-se necessário entender questões a cerca desse viver trazidas no momento do brincar. Enquanto brinca, a criança cria, chora, reflete suas vivências e se enche de alegria(7).

Além disso, sabe-se que a experiência do brincar permite à criança falar sobre o seu sofrimento e, assim, produzir um discurso singular, relacionando real, simbólico e imaginário ${ }^{(8)}$.

Diante do exposto, algumas perguntas surgiram direcionando esse estudo: Como a criança percebe o seu viver com Dermatite Atópica? Como a criança expressa, através do brincar, seus sentimentos em relação à doença e tratamento? Assim, este estudo, teve como objetivo compreender a experiência da criança com Dermatite Atópica em relação ao enfrentamento da doença por meio do conteúdo simbólico expresso na brincadeira, à luz do Interacionismo Simbólico. Trata de um recorte de uma pesquisa que objetivou compreender o significado das vivências da criança com DA em relação ao enfrentamento da doença por meio do conteúdo simbólico expresso na brincadeira, que é uma forma genuína de comunicação que ela utiliza em seu cotidiano.

\section{METODOLOGIA}

Trata-se de estudo de campo, exploratório, com abordagem qualitativa, no qual os dados foram coletados por meio da sessão de Brinquedo Terapêutico (BT) Drámatico, interpretada à luz do Interacionismo Simbólico.

O BT é um brincar estruturado indicado para crianças que vivenciam situações atípicas à sua idade ${ }^{(9)}$. O BT foi utilizado neste estudo, visto que favorece a expressão de desejos, sentimentos, necessidades e medos da criança. Além disso, permite à criança a descarga de sentimentos $^{(9)}$. Por aproximar-se dos ideais pretendidos pelo objeto do estudo, o Interacionismo Simbólico (IS) foi o referencial teórico adotado para a análise dos dados provenientes das sessões de BT.

O IS é uma teoria que trata da relação entre o indivíduo e a sociedade. E que permite ampliar a compreensão dos significados e das experiências referentes à interação deste indivíduo com a situação por ele vivenciada ${ }^{(10)}$.

A coleta de dados ocorreu em uma unidade ambulatorial filantrópica na cidade de São Paulo. Essa é uma unidade na qual são realizados atendimentos multiprofissionais em saúde a crianças e adolescentes. Os atendimentos têm finalidade de prevenção, promoção e recuperação da saúde dessas crianças e adolescentes com diversas doenças crônicas. Umas das doenças com maior número de crianças atendidas no local são as crianças com dermatite atópica.

Participaram da pesquisa nove crianças com idade entre quatro e seis anos, atendidas no referido ambulatório que contemplaram os critérios de inclusão: ter Dermatite Atópica; estar na fase pré-escolar; não apresentar nenhum comprometimento cognitivo e estar em condição física para poder brincar durante a fase de coleta de dados.

Foram escolhidas crianças dentro da faixa etária pré-escolar por serem as mais acometidas pela doença ${ }^{(3)}$. Nesta fase de vida, também, a simbolização e a imaginação durante a brincadeira são mais com- plexas, mesmo que a expressão por meio da linguagem verbal ainda seja limitada ${ }^{(4)}$.

Essas crianças, juntamente com seus familiares, foram abordadas no ambulatório, convidadas a participar de uma sessão de Brinquedo Terapêutico Dramático e assentiram em participar da pesquisa. A coleta de dados ocorreu entre março e maio de 2016.

O número de crianças participantes desse estudo foi definido ao longo da coleta de dados, dessa forma, quando os dados coletados se repetiram e foram adequados para responder aos questionamentos propostos pelo estudo, a coleta de dados foi interrompida ${ }^{(7)}$.

Para a coleta de dados, em ambiente apropriado dentro do ambulatório, foi realizada entrevista com a criança, mediada por uma sessão individual de Brinquedo Terapêutico Dramático e entrevista com a família. A entrevista com a família teve por finalidade conhecer a realidade em que a criança está inserida e, então, obter subsídios para a análise dos discursos das sessões de BT e posterior tratamento dos dados. As sessões tiveram duração, em média, de 15 a 45 minutos.

Os dados foram analisados seguindo-se as etapas preconizados pela Análise Qualitativa de Conteúdo (AQC). A AQC é uma interpretação subjetiva do conteúdo a partir de uma classificação sistemática de codificação dos discursos ${ }^{(11)}$.

Através da AQC, em sua modalidade convencional, são definidos códigos, os quais emergem do próprio discurso. A partir da existência de muitos códigos, o pesquisador pode agrupá-los em categorias e subcategorias, partindo de suas concordâncias, consequências ou antecedentes. A partir de então, dá-se a análise de cada uma dessas categorias, possibilitando a análise dos dados ${ }^{(11)}$. Essas etapas foram direcionadas à luz do Interacionismo Simbólico, o qual é uma teoria que refere-se a interação social das pessoas, dos sentimentos e de atitudes construídas a partir dos significados atribuídos aos objetos e símbolos pelos indivíduos $^{(10)}$. Ele proporciona ampliar a compreensão de significados e experiên- 
cias referentes à interação entre indivíduos a partir de uma situação vivenciada ${ }^{(10)}$.

A condução do estudo respeitou todas as prerrogativas da Resolução n. ${ }^{\circ} 466$, de 2012, do Conselho Nacional de Saúde (CNS), referente a pesquisa com seres humanos, com aprovação pelo Comitê de Ética e Pesquisa do Hospital Israelita Albert Einstein, com o parecer n. ${ }^{\circ}$ 1.369.240.

A participação das crianças foi voluntária e autorizada pelos pais ou responsáveis, após esclarecimentos sobre o estudo. Essa participação, também foi assentida por cada criança, no momento da coleta de dados, quando era explicado, por meio de ilustrações, a sua participação na sessão de Brinquedo Terapêutico, o tempo necessário para a sessão, assim como, sobre a necessidade de devolução dos brinquedos após o final da sessão de BT.

Os dados coletados foram gravados em vídeo para que fossem revisitados ao longo do processo de análise de dados, foi solicitada autorização para uso de imagem também.

\section{RESULTADOS}

O viver com a Dermatite Atópica gera uma rotina para a criança permeada por uma série de cuidados e limitações. Essas limitações decorrem em função da doença e da prevenção de sua exacerbação. Da análise dos dados da pesquisa, surgiram categorias temáticas representativas do viver com a Dermatite Atópica pela ótica dessas crianças que revelaram o desconforto físico causado por esta condição, a preocupação com a aparência física decorrente dela e a rotina constante de cuidados com a saúde e de limitações aos fatores de exposição. A categoria que marca o enfrentamento da criança é aquela onde ela se percebe como um herói na luta contra a doença. A categoria será apresentada a seguir.

"Percebendo-se como um herói na luta contra a doença"

Esse estudo traz resultados e reflexões acerca da categoria "Percebendo-se como um herói na luta contra a doença", que re- trata a luta da criança para convier com a doença. Além disso, essa é uma categoria que traduziu o simbolismo e a percepção da criança fortalecida diante do viver com a dermatite atópica ao se perceber como um herói enfrentando suas limitações e tentando vencê-las a cada dia.

A categoria temática é fruto das interações de uma criança, do sexo masculino com cinco anos de idade, que apresenta as manifestações da DA desde os 11 meses de vida. Atualmente, ele tem a doença em grau moderado, associado a um quadro de asma e intolerância à lactose. Esta condição reflete em uma série de restrições em seu dia a dia, incluindo o uso de medicamentos por via inalatória, tópica e oral para controle das manifestações da doença. A família refere que os principais fatores que exacerbam a DA são pó/poeira doméstica, animais e o frio. Para preservar a identidade da criança, foi atribuído a ele o nome fictício de "Capitão América".

Durante o brincar, o Capitão América traduz simbolicamente o que significa viver com a Dermatite Atópica mostrando ter conhecimento a respeito dos aspectos que exacerbam a sua doença. Ele representa esse entendimento por meio de personagens em uma luta simbólica. A seguir, serão apresentados alguns trechos da sessão de BT que evidenciam mais claramente essa simbolização. As frases representativas da criança estão indicadas com a letra " $\mathrm{C}$ " e as da pesquisadora com a letra " $\mathrm{P}$ ".

Ao iniciar a sessão de BT, ele explora a sacola de brinquedos e seleciona todos os brinquedos necessários para a dramatização da situação criada na sua imaginação. E após selecionar os brinquedos e montá-los, dá início a dramatização.

C: Começa a mexer nas peças de montar, encaixa a peças, fazendo algo sem forma

P: Você tá montando o que Capitão América?

C: Um negócio! [...] É um robô! C: Ele é coberto de força. [...] C: Volta a encaixar as peças e fala: Esse que eu tô construindo é o mal [...] depois eu vou ouvir o bem!
A medida que organiza os brinquedos, Capitão América verbaliza o que está pretendendo abordar na brincadeira. E assim, ele relaciona os fatores que desencadeiam a doença ao personagem que ele chama de mal. E constrói outro personagem que representa o bem, a quem ele denomina de "cobra". Além disso, mantém esse personagem do bem mais próximo a si do que os outros personagens da brincadeira.

C: Primeiro esse, depois esse aqui (fala enquanto termina de encaixar as peças)

O mal é estranho sabia?

P: Quem é o mal?

C: As sombras! E o pó!

P: O pó?

C: É o pó é rui(m)!

P: O pó é mal? Por quê?

C: Por que ele não gosta! Ele não gosta do robô (fala e pega pra junto de si, o primeiro boneco que montou)

$P$ : E o que é que o mal faz?

$\mathrm{C}: \mathrm{O}$ pó vai destruir o robô.

$P$ : E quem mais é do mal?

C: O "fri(o)"

P: Quem é o fri(o)?

C: Ele também [...] ele mora com o pó

[...] na escuridão!

C:- O bem é uma cobra! (Fala já com o boneco do bem montado, terminando de encaixar algumas peças) [...]

P: O Capitão América é esse robô? (Aponto para o robô do bem).

C: É.

Após montar os seus dois robôs, ele reafirma que o pó é algo ofensivo ao bem e traz para próximo de si o boneco do bem, transmitindo simbolicamente que o bem é algo próximo de si. Ao ser questionado pela pesquisadora sobre o que o pó faz com o bem, ele responde que o pó tenta matar o bem.

P:E esse robô é o que?

C: É o bem! E o bem tem uma espada de fogo! 
P: Aí o pó faz o que com ele?

C: Tenta matar ele!

P: Por quê?

C: Porque o pó mora lá na escuridão.

Além de construir os bonecos, ele também monta espadas a serem utilizadas na luta, mostrando que para enfrentar essa luta, ele precisa de armas e aliados.

C: É a espada de sombra, do sol e a espada do fogo.

P: E de quem são essas espadas?

C: É do bem!

Depois de montar os dois robôs ele brinca durante toda a sessão de BT representando a luta entre os dois e fala que um dos robôs solta um veneno chamado de "golpe super forte", para ajudá-lo a matar o mal. Ele usa esse termo diversas vezes durante a brincadeira simbólica, a cada vez que o boneco do mal parece se sobressair na luta. Com o propósito de representar que nas situações onde o mal parece se sobressair, a criança reforça a necessidade do robô do bem usar um golpe super forte para ganhar esta luta.

C: Phuu (imita sons de lutas) [...] Golpe super forte! (fala isso e olha para pesquisadora)

Golpe super forte! Sabe o que é golpe super forte?

P: Não!

C: É um veneno que eu solto!

P: É? E pra que é esse veneno?

C: É um golpe super forte, veneno da boca dele, pra tá derrotando o robô! Golpe super forte! (Fala repetidas vezes) P:- Você tá derrotando o robô então? C: É! O robô tá morrendo! Golpe super forte $[\ldots]$ thuu! Golpe super forte [...]

Dessa forma, ele conduz toda a sessão de BT, sem se interessar pelo demais brinquedos disponíveis, parecendo conseguir expressar todas as vivências e desejos com o que construiu. Ao ser avisado que o tempo da brincadeira estava se encerran- do, rapidamente finaliza a luta, colocando o bem como grande vencedor e referindo que o mal "caiu em um buraco negro".

P: Capitão América, o nosso tempo tá acabando, tá bom?

C: Han ram. C: (Continua a luta, parecendo já finaliza-lá), enquanto fala: Golpe super forte! E o golpe super forte $[. .$.$] agr [...] puuu [...] fuuu [...]$ traaa (imita alguns sons). Golpe desaparecer [...] Ahhhhhh [...]

$\mathrm{P}$ : O que aconteceu?

C: Golpe desaparecer! Ele desapareceu [...] desapareceu! Caiu num buraco negro.

C: Uhhh [...] a cobra ganhou!

P: A cobra que ganhou?

C: É!

Ao finalizar a brincadeira, o Capitão América ajuda a pesquisadora a guardar os brinquedos na sacola, se despede e sai com uma expressão facial de alegria, demostrando ter expressado tudo que desejava naquele momento.

\section{DISCUSSÃO}

O estudo traz, sob a ótica da criança, o modo de enfrentamento dela em relação a uma doença comum na vida de muitas crianças mas que, muitas vezes, não recebe a atenção aos problemas emocionais que causa para quem tem que conviver com ela. A realização deste estudo avançou no conhecimento sobre o tema e pôde auxiliar o enfermeiro na decisão por ações centradas na criança e em sua perspectiva.

Sob a ótica do Interacionismo Simbólico, foi possível perceber o significado que a criança atribuiu a sua luta contra a doença, como (re)significa seu papel de doente limitado às condições que a DA impõe e tornando-se ativa na tentativa de controle sobre o sofrimento e tensão.

Os discursos despontaram as restrições impostas às crianças inerentes à condições de se ter DA, bem como como a asma, que ele também apresenta, a qual tem relação com a DA. Enquanto brinca, a criança ex- põe, simbolicamente, a necessidade que tem em se perceber como herói diante da situação que enfrenta, buscando autonomia e empoderamento perante a doença ${ }^{(8)}$. Do mesmo modo, em outro estudo ${ }^{(12)}$, que buscou compreender a experiência de crianças que são submetidas ao isolamento, revelou que no momento da brincadeira a criança torna-se protagonista na história, valorizando-se e tendo voz.

As interações revelaram que as crianças buscam um modo próprio de expressar sua vivência em relação à doença. Um estudo $^{(8)}$ semelhante feito com crianças com doenças crônicas mostrou que elas buscam entender os desdobramentos da doença em sua vida, conferindo uma identidade própria ao seu processo de enfrentamento. Neste sentido, a identidade adotada pela criança é permeada pelo significado que ela confere ao ter que enfrentar a doença, onde se percebe travando uma luta contra a DA e, para isto, precisa desenvolver poderes para conseguir vencer esta guerra.

Nesse processo de (re)significar sua doença, enquanto brinca, desvela-se a catarse em relação ao viver com a doença. Na brincadeira, a criança pode dominar a situação e realizar, com o brinquedo, aquilo que deseja realizar em seu cotidiano $^{(13)}$. Ou seja, ao usar o momento da luta para "atacar" o mal, neste caso a DA e todas as repercussões causadas em sua vida, busca intensamente destruí-lo, resgata poderes sobrenaturais e mais fortes do que o do mal e, assim, libera a ansiedade em relação a esse assunto e pode resolver conflitos próprios ${ }^{(12,13)}$.

Inúmeras vezes, a criança usa o boneco do bem para destruir o mal e, também, utiliza as espadas que criou para exercer sua dominação diante do inimigo e, assim, mostrar o quanto o seu viver com a doença se constitui em uma luta diária para se livrar de algo que é incômodo.

Todas as ações trazidas pela criança no momento da brincadeira refletem o quanto ele vê a doença e o enfretamento dela como uma verdadeira luta. Nessa luta, o tempo todo, ele se representa simbolicamente como herói, mas, ao mesmo 
tempo, demonstra que precisa de ajuda. Ao final de sua luta, consegue vencer esse mal. O que é pertinente à afirmação de que ao brincar, a criança comunica-se ao que the é familiar, contrapondo-se assim à estranheza e à ameaça decorrentes da sua doença e tratamento ${ }^{(14)}$.

O simbolismo trazido na sessão de BT é característico de ações das crianças em fase pré-escolar, momento em que a linguagem verbal ainda é limitada, sendo a simbolização e a imaginação mais complexas e, assim, usadas como facilitadoras da comunicação com a criança ${ }^{(1)}$. Nesta pesquisa, percebeu-se que a brincadeira torna-se momento de prazer e facilita a comunicação do profissional com a criança ${ }^{(12,15)}$.

Esses símbolos são atribuídos pela criança de acordo com a experiência que ela vivencia com a doença, desse modo, aquilo que Ihe causa mal ela traz como representativos do mal. O que aproxima-se bastante das ideias do Interacionismo Simbólico, segundo o qual o indivíduo age em relação ao mundo baseando-se nos significados que o mundo lhe oferece ${ }^{(10)}$.

Um ponto forte a ser destacado nessa luta é a figura representativa do mal, que ele específica como o pó e o frio, fatores exacerbantes da sua condição de saúde e doença. Essa ação aproxima-se muito da literatura referente à dermatite atópica, que traz a doença como algo de causa multifatorial e ligada a diversos fatores que exacerbam as crises da doença. Entre os principais alérgenos existentes e capazes de desencadear uma crise atópica incluem pó, ácaros e pólen ${ }^{(3)}$.

Outra questão simbólica bastante expressiva é o uso de espadas e de um "golpe super forte" para vencer a doença, ou seja, ações competentes devem ser aplicadas, resgatando a sua própria força para ir contra algo que é quase incontrolável. O que parece remeter-se as armas fortes que ele usa para vencer o inimigo, como os medicamentos que ele precisa tomar ou usar sempre que a doença parece estar perto de "ganhar a luta".

\section{CONCLUSÃO}

Esse estudo possibilitou compreender a experiência vivenciada pela criança pré-escolar com dermatite atópica e entender como esta condição interfere em sua vida, nas suas relações sociais e na interação com o ambiente à sua volta. Permitiu entender que a criança se percebe como um herói diante dessa vivência, travando diariamente uma luta contra a doença e tentando vencê-la a cada dia. Essas repostas emergiram do brincar, o que revela que a criança reflete sobre sua experiência por meio da brincadeira, possibilitando ao adulto compreender a perspectiva dela em relação à sua própria experiência.

$\mathrm{O}$ brinquedo mostrou-se como um aliado da criança no enfrentamento da doença, promovendo a catarse, caracterizada pelo prazer, satisfação e alívio da tensão decorrente da sua condição. Além disso, mostrou-se como importante ferramenta de coleta de dados que permite à criança expressar-se com liberdade, é terapêutico e facilita a aproximação do profissional com ela e, por conseguinte, pode aprimorar a qualidade da assistência de enfermagem.

Recomenda-se que esta modalidade terapêutica seja utilizada rotineiramente nos serviços de saúde, visto que se constitui em uma valiosa oportunidade de reflexão para a criança em relação ao seu problema de saúde, a compreensão de alguns conceitos sobre a doença e a minimização da ansiedade e das dificuldades de conviver com a DA.

Além disso, incentiva-se que outros estudos, sob essa mesma problemática sejam efetivados, com fins de se ampliar a possiblidade de voz dada as crianças que convivem com essa doença.

Extraído da dissertação de mestrado intitulada Vivendo uma luta entre o bem e o mal: o impacto da dermatite atópica nas interações da criança, revelado por meio do brinquedo terapêutico.

\section{Referências}

1. Kliegman RM, Stanton BF, Schor NF, St. Geme JW, Behrman RE. Nelson tratado de pediatria. Tradução de Silvia Mariângela Spada. 19. ed. Vol. 1. Rio de Janeiro: Elsevier; 2014.

2. Roxo Junior $P$, Ferreira $\mathrm{Cl}$. Dermatite atópica. In: Campos Júnior $\mathrm{D}$, Burns DA, organizadores. Tratado de pediatria: Sociedade Brasileira de Pediatria. 3. ed. Vol. 1. Barueri: Manole; 2014. p.689-92. Capítulo 10.

3. Kang K, Polter AM, Nodorost ST, Stevens SR, Cooper KD. Dermatite atópica. In: Bolognia JL, Jorizzo JL, Papinni RP. Dermatologia. Rio de Janeiro: Elsevier; 2011. p.181-95. Capítulo 13.

4. Azulay RD, Azulay DR, Abulafia LA. Dermatologia. 6. ed. Rio de Janeiro: Guanabara Koogan; 2013.

5. Simão HM. Dermatite atópica. In: Sociedade Brasileira de Pediatria. Alergia e imunologia [Internet]. 2014 [citado 2019 abr 08]. Disponível em: http://www.sbp.com.br/src/uploads/2015/02/daportalsbp-helio2014.pdf 6. Amaral CS, Sant'anna CC, March M de F. Quality of life in children and teenagers with atopic dermatitis. An Bras Dermatol. 2012; 87(5):717-23. 7. Surdi AC, Medki JP, Kunz E. O brincar e o "se-movimentar" da criança como manifestação artística. [Internet] 2016 [citado abr 20] Disponível em: https://periodicos.ufmg.br/index.php/licere/article/view/1293/900. 8. Matos APK, Canela PC, Silveira AO, Wernet M. Revelações manifestadas por crianças pré-escolares portadoras de doenças crônicas em tratamento ambulatorial. Acta Paul Enferm. 2014; 27(2):126-32.

9. Ribeiro CA, Maia EB, Sabatés AL, de Borba RI, Rezende MA, de Amorim Almeida F. Mesa redonda: o brinquedo e a assistência de enfermagem à criança. Enferm Atual. 2002; 2(24):6-17.

10. Charon JM. Symbolic Interacionism: na introduction, na interpretation, na interation. 10. ed. New Jersey: Prentice Hall; 2010.

11. Hsieh HF, Shannon SE. Three approaches to qualitative content analysis. Qual Health Res [Internet] 2005 [cited 2015 June 12]; 15(9):1277-88. Available from: http://qhr.sagepub.com/content/15/9/1277.full.pdf+html 12. Depianti JRB, Melo LL, Ribeiro CA. Brincando para continuar a ser criança e libertar-se do confinamento da hospitalização em precaução. Rev Esc Anna Nery. 2018; 22(2).

13. Giacomello KJ, Melo LL. Do faz de conta à realidade: compreendendo o brincar de crianças institucionalizadas vítimas de violência por meio do brinquedo terapêutico. Ciênc Saúde Coletiva. 2011; 16(1):1571-80. 14. Oliveira RR. A brinquedoteca no contexto hospitalar pediátrico: o cotidiano da enfermagem [dissertação]. [Rio de Janeiro]: Universidade Federal do Rio de Janeiro, Escola de Enfermagem Anna Nery; $2012.102 \mathrm{f}$. 15. Pennafort VPS, Queiroz MVO, Gomes ILV, Rocha MFF. Brinquedo terapêutico instrucional no cuidado cultural da criança com diabetes tipo 1. Rev Bras Enferm. 2018;71(suppl 3):1415-23 